\title{
Elective cholecystectomy after reversal of septic shock using multimodality endoscopic gallbladder drainage
}

Endoscopic ultrasound-guided gallbladder drainage (EUS-GBD) is considered an effective therapy for acute cholecystitis in patients who are unfit for surgery [13].

We describe the case of a 90-year-old woman admitted for septic shock due to acute cholecystitis, who underwent EUS-GBD after being considered unfit for surgery because of advanced age and comorbidities (obesity, coronary heart disease) (\Video 1). Transgastric EUSGBD with a lumen-apposing metal stent (Hot-Axios, $10 \times 10 \mathrm{~mm}$, Boston Scientific, Marlborough, Massachusetts, USA) was performed using a forward-view echoendoscope (TGF-UC180]; Olympus, Tokyo, Japan) after failure in identifying a safe window with a curvilinear-array echoendoscope [4]. Subsequently, the patient recovered and returned home after 1 week.

However, she was readmitted after 2 weeks because of recurrence of cholangitis and severe sepsis. Computed tomography showed cholecystitis despite the stent still being in place. Almost complete stent occlusion due to tissue overgrowth was observed endoscopically. The gallbladder lumen contained a large amount of pus, which was drained using a nasobiliary tube, leading to a temporary clinical improvement. At multidisciplinary discussion, surgery was still contraindicated due to sepsis and hemodynamic instability, and therefore an endoscopic rescue strategy was planned. We placed a fully covered biliary metal stent over a guidewire through the obstructed Axios, achieving good biliary drainage [5].

Two months later, due to the persistence of biliary pain and ultrasound signs of mild cholecystitis, without systemic sep-

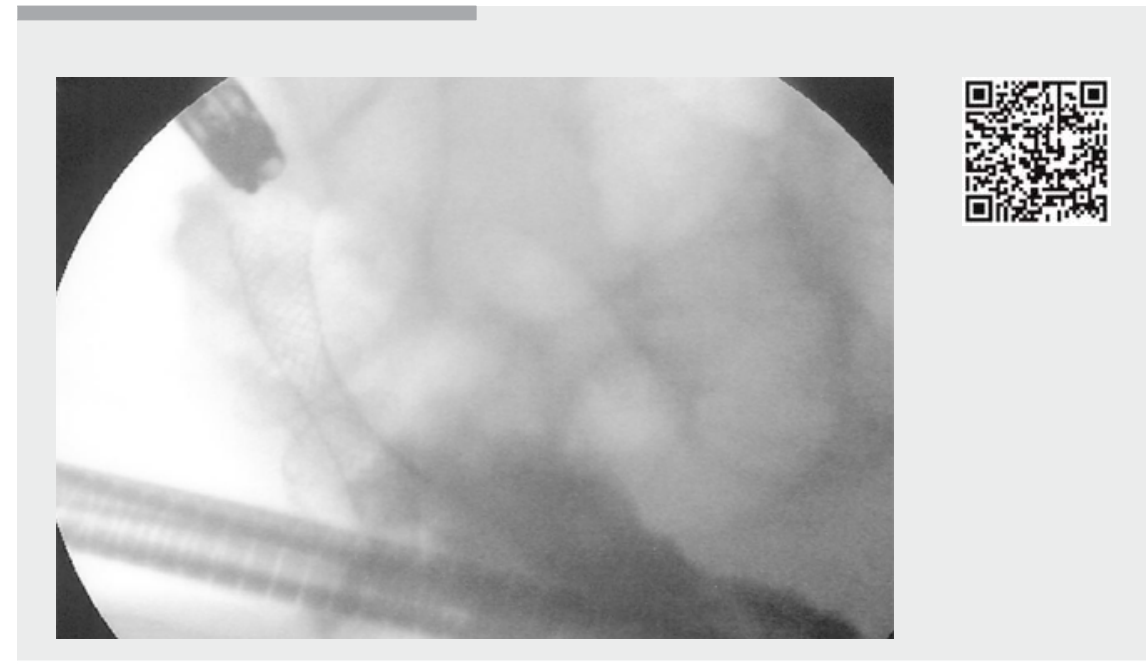

Video 1 Endoscopic ultrasound-guided gallbladder drainage with a lumen-apposing metal stent; endoscopic view of the proximal flange deployment. Computed tomography showing recurrent cholecystitis, stent still in place, and gastric tissue overgrowth; endoscopic view of nearly complete stent occlusion due to tissue overgrowth, and gallbladder lumen with pus and debris. Endoscopic and fluoroscopic view of a biliary metal stent placed through the obstructed Axios stent (Boston Scientific, Marlborough, Massachusetts, USA). Elective open cholecystectomy, showing the two metal stents between the gastric antrum and gallbladder.

sis, the patient was considered suitable for elective cholecystectomy. Surgery was not impeded by the presence of the stents. In particular, disconnecting the gallbladder and suturing the gastric wall were undemanding.

We speculate that the suboptimal clinical outcome of EUS-GBD in our patient might have been due to the greater distance between the gallbladder and the antrum, as opposed to the duodenum, leading to traction on the stent and subsequent tissue overgrowth. We showed that surgery could be an effective rescue strategy, even after failure of EUS-GBD.

Endoscopy_UCTN_Code_CPL_1AL_2AD

\section{Competing interests}

None

The authors

Pietro Fusaroli ${ }^{1}$, Marta Serrani ${ }^{1}$, Sandro Sferrazza ${ }^{1}$, Romano Linguerri², Elio Jovine ${ }^{2}$, Andrea Lisotti ${ }^{1}$

1 Gastroenterology Unit, Department of Medical and Surgical Sciences University of Bologna, Hospital of Imola, Imola, Italy

2 Surgery Unit, Hospital of Imola, Imola, Italy 


\section{Corresponding author}

\section{Pietro Fusaroli, MD}

Gastroenterology Unit, Hospital of Imola, Department of Medical and Surgical Science, University of Bologna, Via Montericco 4, 40026 Imola, Italy

Fax: +39-0542-662409

pietro.fusaroli@unibo.it

\section{References}

[1] Fabbri C, Luigiano C, Lisotti A et al. Endoscopic ultrasound-guided treatments: are we getting evidence based - a systematic review. World J Gastroenterol 2014; 20 : $8424-8448$

[2] Dollhopf M, Larghi A, Will U et al. EUS-guided gallbladder drainage in patients with acute cholecystitis and high surgical risk using an electrocautery-enhanced lumenapposing metal stent device. Gastrointest Endosc 2017; 86: 636-643
[3] Irani S, Ngamruengphong S, Teoh A et al. Similar efficacies of endoscopic ultrasound gallbladder drainage with a lumen-apposing metal stent versus percutaneous transhepatic gallbladder drainage for acute cholecystitis. Clin Gastroenterol Hepatol 2017; 15: $738-745$

[4] Fusaroli P, Serrani M, Lisotti A et al. Performance of the forward-view echoendoscope for pancreaticobiliary examination in patients with status post-upper gastrointestinal surgery. Endosc Ultrasound 2015; 4 : $336-341$

[5] Fabbri C, Luigiano C, Marsico M et al. A rare adverse event resulting from the use of a lumen-apposing metal stent for drainage of a pancreatic fluid collection: "the buried stent”. Gastrointest Endosc 2015; 82: 585 587

\section{Bibliography}

DOI https://doi.org/10.1055/a-0655-1881

Published online: 14.8.2018

Endoscopy 2018; 50: E299-E300

(c) Georg Thieme Verlag KG

Stuttgart · New York

ISSN 0013-726X
ENDOSCOPY E-VIDEOS

https://eref.thieme.de/e-videos

回局 Endoscopy E-Videos is a free

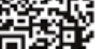
access online section, reporting on interesting cases and new techniques in gastroenterological endoscopy. All papers include a high quality video and all contributions are freely accessible online.

This section has its own submission website at https://mc.manuscriptcentral.com/e-videos 